\title{
CHARACTERIZATION OF HANFORD TANK WASTES CONTAINING FERROCYANIDES
}

J. M. Tingey

RECEVES

J. D. Matheson

S. G. McKinley

T. E. Jones

K. H. Pool

February 1993

Presented at the WM Symposia 1993 Conference

February 29 - March 4, 1993

Tucson, Arizona

Prepared for

the U.S. Department of Energy

under Contract DE-AC06-76RLO 1830

Pacific Northwest Laboratory

Richland, Washington 99352

\section{DISCLAIMER}

This report was prepared as an account of work sponsored by an agency of the United States Government. Neither the United States Government nor any agency thereof, nor any of their employees, makes any warranty, express or implied, or assumes any legal liability or responsibility for the accuracy, completeness, or usefulness of any information, apparatus, product, or process disclosed, or represents that its use would not infringe privately owned rights. Reference herein to any specific commercial product, process, or service by trade name, trademark, manufacturer, or otherwise does not necessarily constitute or imply its endorsement, recommendation, or favoring by the United States Government or any agency thereof. The views and opinions of authors expressed herein do not necessarily state or reflect those of the United States Government or any agency thereof. 


\section{DISCLAIMER}

Portions of this document may be illegible in electronic image products. Images are produced from the best available original document. 
CHARACTERIZATION OF HANFORD TANK WASTES CONTAINING FERROCYANIDES

J.M. Tingey, J.D. Matheson, S.G. McKinley, T.E. Jones, and K.H. Pool, Pacific Northwest Laboratory

\section{INTRODUCTION}

During the 1950 's, radiocesium was scavenged from aqueous nitratecontaining wastes to obtain additional waste storage space at the Hanford site. The radiocesium was scavenged by adding sodium or potassium ferrocyanide and nickel sulfate to waste from the uranium recovery, process. In this scavenging process, the cesium in the supernatant of this waste stream was precipitated as cesium nickel ferrocyanide $\left[\mathrm{NiCs}_{2} \mathrm{Fe}(\mathrm{CN})_{6}\right]$. Excess sodium existed in this waste stream; therefore, the primary constituent of the precipitate from this process was sodium nickel ferrocyanide. Often strontium was also scavenged from the supernatant. By removing the cesium and strontium, the concentration of the long lived radioisotopes was sufficiently reduced in the supernate that the supernate could be transferred to cribs on the Hanford site. The removal of the supernate provided the needed waste storage space in these underground tanks.

Currently, 17 storage tanks on the Hanford site that are believed to contain > 1000 gram moles (465 lbs) of ferrocyanide compounds have been identified. Seven other tanks are classified as ferrocyanide containing waste tanks, but contain less than 1000 gram moles of ferrocyanide compounds. These seven tanks are still included as Hanford Watch List Tanks.

After the radiocesium scavenging processes were completed and storage space was obtained, other waste types were added to those tanks which contained the ferrocyanide precipitates. These tanks have been declared an unreviewed safety question (USQ) because of potential thermal reactivity hazards associated with the ferrocyanide compounds and nitrate and nitrite.

Cyanides are strong reductants and are known to react explosively with nitrates, nitrites, chromates, and other strong oxidants. The explosive behavior of cyanides with nitrates and nitrites has been reported for many years (Hepworth et a1. 1957, Cooper 1957, and Sax 1957) and is the basis for an Austrian explosives patent (Eiter et al. 1954).

Since the mid $1980^{\prime} s$, the potentially explosive reactions of ferrocyanides with nitrates and nitrites have been studied at the Pacific Northwest Laboratory with both synthetic and actual tank wastes (Burger 1984, Burger et al. 1988, Burger et a1. 1991, and Scheele et al. 1992). Hanford tanks with waste containing > 1000 gram moles of ferrocyanide have been sampled. Extensive chemical, radiochemical, and physical characterization have been performed on these waste samples. The reactivity of these wastes were also studied using Differential Scanning Calorimetry (DSC) and Thermogravimetric analysis.

${ }^{1}$ Pacific Northwest Laboratory is operated by Battelle Memorial Institute for the U.S. Department of Energy under Contract DE-AC06-76RLO 1830. 


\section{EXPERIMENTAL APPROACH}

Tank waste simulants were prepared following the cesium scavenging flowsheets used at Hanford in the 1950's (S10at 1954; Schmidt and Stedwel1 1954). Actual tank waste samples were retrieved from tank 241-C-112 using a specially designed and equipped core-sampling truck. This core sampling method is used to preserve waste stratification, collect samples within 3 inches of the bottom of the tank, minimize the radiation exposures and potential for releases of radioactive materials, and prevent any thermal or spark initiation of ferrocyanide reactions. The core sampling truck obtain samples in samplers which are 19" in length and $7 / 8^{\prime \prime}$ in diameter with a volume of $190 \mathrm{ml}$. Each sample is identified as a segment with the first sample being obtained from the top of the tank. Successive 19 inch samples are obtained until the entire tank depth has been sampled. Two 19 inch segments were needed from Tank 241-C-112 to characterize the entire depth of the waste in this tank.

The tank waste samples were transferred to a shielded radiochemistry facility (PNL's High-Level Radiochemistry Facility also called the 325-A HotCell facility) which was designed to handle highly radioactive material. The samples were retrieved from the core sampler and processed as shown in Figure 1. During this process the tank sample was subsampled at 4.75 inch long intervals along the core. These samples are called quarter segments, since four of these samples are taken from a 19 inch segment. These samples were then analyzed for chemical and radiochemical composition, physical properties, and thermal behavior. A composite of the entire core was also prepared which was analyzed more extensively than the quarter segments. The analyses performed on the quarter segments and core composite are given in Table 1.

\section{ANALYSIS}

Only a small portion of the data obtained from this characterization effort will be reported in this paper. The characterization data for this tank has been reported in three core data reports by SG McKinley et a1. 1992. This report will deal primarily with the cyanide and carbon analyses, thermal analyses, and limited physical property measurements.

Total cyanide analyses was performed using a microdistillation method which was modified for use in shielded radiochemistry facilities. The sample was dissolved with a solution $0.17 \mathrm{M}$ in EDTA and $0.83 \mathrm{M}$ in ethylenediamine. The dissolved sample was then distilled with a $\mathrm{H}_{2} \mathrm{SO}_{4} / \mathrm{MgSO}_{4}$ releasing solution and a $\mathrm{NaOH}$ trap solution. The distillation was performed at a temperature of $125^{\circ} \mathrm{C}$. The distillate was then analyzed for cyanide using an argentometric titration. The total cyanide analyses method is effective for waste tank samples where the concentration of total cyanide is greater than approximately 0.1 weight percent. The detection limit for this procedure is approximately $20 \mu \mathrm{g}$ cyanide.

Carbon analyses including total carbon, total organic carbon, and total inorganic carbon was performed using a hot persulfate method. The samples were acidified with heated sulfuric acid converting the inorganic carbon to $\mathrm{CO}_{2}$. The $\mathrm{CO}_{2}$ was swept to a coulometry detector with an $\mathrm{O}_{2}$ carrier gas. The organic carbon was then converted to $\mathrm{CO}_{2}$ with potassium persulfate and a silver catalyst. The $\mathrm{CO}_{2}$ was measured in the same manner as used to determine 


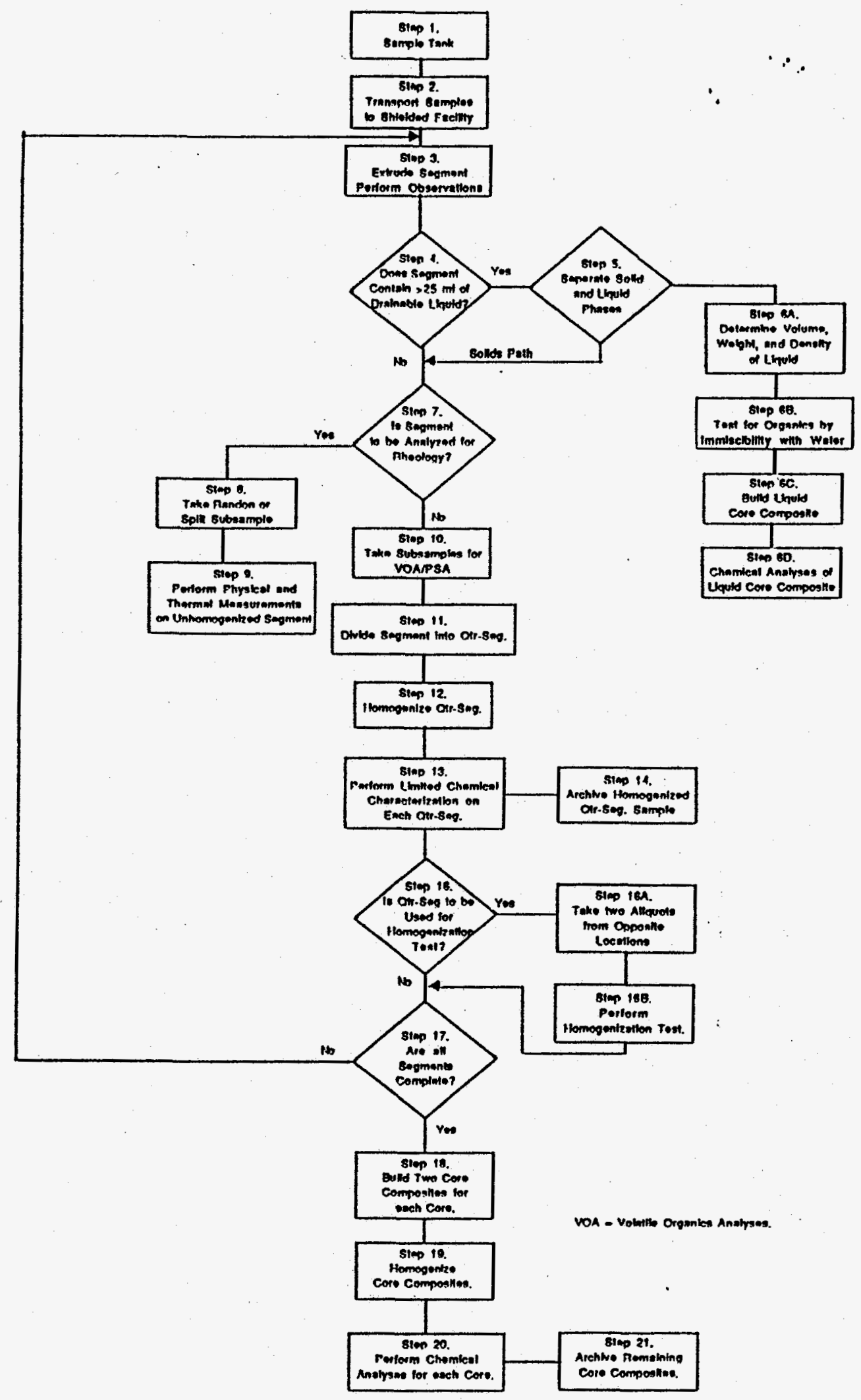

FIGURE 1. Tank 241-C-112 Core Sample Flowsheet 
the inorganic carbon. The total carbon was calculated as the sum of the inorganic and organic carbon concentrations or was measured directly by initially adding the heated sulfuric acid, potassium persulfate, and silver catalyst to the sample in a one step process. With this method both the inorganic and organic carbon in the sample were oxidized to $\mathrm{CO}_{2}$.

Scanning thermogravimetry (STG) and differential scanning calorimetry (DSC) were performed on the homogenized quarter segments and the core composite sample. These two thermal analys is techniques are useful in determining the thermal stability or reactivity of a material. DSC measures heat released or absorbed while the temperature of the sample is increased at a constant rate. STG measures the mass of a sample while the temperature of the sample is increased at a constant rate. Both methods can be modified to measure isothermal changes in the material.

DSC is often used to measure thermal decomposition temperatures, heats of reaction, reaction temperatures, melting points, and solid-solid transition temperatures. STG is used to measure thermal decomposition temperatures, water contents, and reaction temperatures. The two methods often provide complimentary information.

The calibration of the differential scanning calorimeter and the thermogravimetric analyzer were checked before running these samples. An indium standard was run on the calorimeter to check the temperature and enthalpy calibrations. The balance calibration of the thermogravimetric analyzer was checked with a $100 \mathrm{mg}$ standard weight, and the temperature calibration of the analyzer was checked with alumel and perkalloy curie point magnetic transition standards. The temperature and enthalpy calibration checks were all within $2^{\circ} \mathrm{C}$ and $0.2 \mathrm{~J} / \mathrm{gm}$ of their reported values, and the balance calibration was within $0.01 \mathrm{mg}$.

RESULTS

The concentrations of nitrate, nitrite, total organic carbon, and free cyanide of samples from all three core samples taken from tank 241-C-112 (cores 34,35 , and 36 ) are given in Table 2. The activities of ${ }^{137} \mathrm{Cs}$ and ${ }^{90} \mathrm{Sr}$ from these same samples are also reported in Table 2. These compounds are key in understanding the reactivity of the materials in this tanks. Each of these core samples was obtained from a different position in the tank.

Anion analysis indicated that the primary anions of those measured (fluoride, chloride, nitrite, nitrate, sulfate, phosphate, and free cyanide) in tank 241-C-112 were nitrate and nitrite. A significant amount of phosphate was also observed, but the concentration of phosphate (approximately $1.8 \mathrm{wt} \%$ ) was significantly smaller than nitrite or nitrate. The ratio of these anions to the ferrocyanide present is much larger than the stoichiometric ratio required for total oxidation of the ferrocyanide (six moles of nitrate or 10 moles of nitrite per mole of ferrocyanide).

The measurement of total organic carbon provides some insight into the amount of cyanide which may be present in the sample. Carbon analyses using combustion methods tend to give more reproducible cyanide analys is than does the hot persulfate method. Analysis of simulated ferrocyanide containing wastes by combustion at $700^{\circ} \mathrm{C}$ (total organic carbon) or at $1000^{\circ} \mathrm{C}$ (total 
carbon) give cyanide recoveries between 90 and 105\%. The recoveries observed with the hot persulfate method for carbon analysis were between 55 and $60 \%$. Therefore, the concentration measured for total organic carbon by combustion and hot persulfate methods provides an approximation for the concentration of cyanide present as ferro- and ferri-cyanide complexes. The mean concentration of organic carbon in the tank as measured by the hot persulfate method is 0.3 wt\%. If all of the measured organic carbon concentration was in the form of cyanide, the cyanide concentration would be between .7 wt\% and 1.2 wt\% (assuming a $55 \%$ recovery of cyanide).

The data in Table 2 indicates that the measured total organic carbon concentration decreases as one approaches the bottom of the tank. Limited data on the nickel concentration in the tank also indicates a significant decrease in the nickel concentration near the bottom of the tank. The thermal analysis data from core 36 also indicates that the ferrocyanide concentration at the bottom of the tank is substantially lower than near the surface of the waste. This trend in ferrocyanide concentration is particularly obvious for core 36 where the measured total organic carbon concentration and ${ }^{137} \mathrm{Cs}$ activity decrease near the bottom of the tank.

The concentration of free cyanide (approximately $0.1 \%$ ) in the tank as shown in Table 2 is significantly lower than the ferrocyanide concentration estimated from the total organic carbon measurements, but is still substantial in the these tank wastes.

Water leach data on these samples indicates that only a minimal amount of the iron, nickel, and Cs present in the tank samples is soluble. The fact that the $\mathrm{Cs}_{\mathrm{s}}$ is not soluble indicates that most of cesium in these solids is complexed. It is expected that this cesium is complexed in the form of cesium nickel ferrocyanide.

Total cyanide analysis was performed on a single sample obtained from this tank (quarter segment 20 from core 34 ) due to the developmental nature of this method and the limited amount of sample available. Five aliquots from this sample were analyzed using the ethylenediamine/EDTA dissolution and microdistillation method. The total cyanide present in this sample was $0.45 \pm$ 0.06 wt\%. This concentration compares well with the measured organic carbon concentration for this quarter segment $10.15 \mathrm{wt} \%$ as carbon or $0.33 \mathrm{wt} \%$ as cyanide with no correction for percent recovery). The total organic carbon of this sample was also measured using the combustion method at $1000^{\circ} \mathrm{C}$. The carbon concentration obtained from this measurement was $1.12 \pm 0.16 \mathrm{wt} \%$ carbon or $2.5 \mathrm{wt} \%$ cyanide if all the carbon were cyanide.

Two simulated ferrocyanide containing wastes of known concentrations were also analyzed by this method. The analysis of these simulated wastes indicated that this method produces cyanide recoveries between 90 and $96 \%$. When the core sample was spiked with these simulated ferrocyanide wastes and a potassium ferrocyanide of known concentration the percent recoveries were between 83 and $96 \%$. These recoveries indicate that the total cyanide concentration in this sample may be biased 15 to $20 \% 10 \mathrm{w}$.

Differential scanning calorimetry (DSC) and scanning thermogravimetry (STG) were performed in duplicate on each of the samples obtained from tank 241-C-112. In the DSC scans and STG thermograms of these samples several 
transitions were observed. The temperature range, onset temperature, and enthalpy for each of these transitions is given in Table 3.

Many ferro- and ferri-cyanide compounds as well as simulated ferrocyanide containing waste samples have also been analyzed by these thermal techniques. The results from these non-radioactive samples indicate that the oxidation of ferro- and ferri-cyanide by nitrite and/or nitrate is a complex series of reactions (Burger et a1. 1991). An example of the DSC scan and STG thermograms of these materials is given in Figure 2.

The first transition observed in the samples from tank $241-C-112$ is an endotherm that begins at the lower temperature limit of the analys is $\left(30^{\circ} \mathrm{C}\right)$ and is essentially complete by about $240^{\circ} \mathrm{C}$. This transition can be divided into at least three transitions, but these transitions are not always resolvable. The most likely reactions occurring in this region $\left(30\right.$ to $\left.240^{\circ} \mathrm{C}\right)$ are the release of bulk and interstitial water, and waters of dehydration. The majority of energy and weight loss in this region occurs between 30 and $170^{\circ} \mathrm{C}$. The entha7py and weight loss associated with this transition is much larger exhibited by any of the other transitions. This is due to the 7 arge amount of water associated with these waste samples.

An exothermic transition is observed over the temperature range from 290 to $350^{\circ} \mathrm{C}$ with an average onset temperature of about $290^{\circ} \mathrm{C}$. The enthalpy of this transition is approximately $-12 \mathrm{~J} / \mathrm{g}$ of sample. This enthalpy is small compared to the enthalpy for the first transition $(\approx 1000 \mathrm{~J} / \mathrm{g}$ of sample).

The final transition is observed over a temperature range from 300 to $400^{\circ} \mathrm{C}$. This transition is endothermic with an enthalpy of approximately 30 $\mathrm{J} / \mathrm{g}$. The onset temperature for this transition ranges from 300 to $330^{\circ} \mathrm{C}$.

Similar behavior has been observed in previous thermal analysis studies of $\mathrm{Cs}_{2} \mathrm{NiFe}(\mathrm{CN})_{6}$ and $\mathrm{Na}_{2} \mathrm{NiFe}(\mathrm{CN})_{6}$. These previous studies were performed on crushed dried materiaf; therefore, the water loss endotherm was not as large as was observed in the $\mathrm{C}-112$ core samples. The concentration of the $\mathrm{Cs}_{2} \mathrm{NiFe}(\mathrm{CN})_{6}$ and $\mathrm{Na}_{2} \mathrm{NiFe}(\mathrm{CN})_{6}$ was al so much higher in the previous studies, so the weight changes and enthaipies observed were much greater. The small enthalpies for the ferrocyanide transitions are indicative of low concentrations of ferrocyanide. This data supports the conclusions drawn from the chemical and radiochemical analyses. As can be seen in Table 3 , the thermal behavior of quarter segments $1 \mathrm{C}, 1 \mathrm{D}, 2 \mathrm{~A}, 2 \mathrm{~B}$, and the composite from core 36 are very similar; but exothermic behavior is not observed in quarter segments $2 \mathrm{C}$ and $2 \mathrm{D}$. This supports the chemical data which indicated that the ferrocyanide content decreases significantly near the bottom of the tank.

The weight percent change observed by STG over the temperature ranges from 30 to $500^{\circ} \mathrm{C}$ is reported in Table 4 . The weight loss observed over the temperature range of the first endothermic transition is a measure of the water associated with these samples. The weight loss associated with this transition ranges from 40 to $60 \%$ indicating that these tank waste samples contain a significant amount of water. This percent water significantly increases the safety of this tank.

A small weight loss $(6 \%)$ is observed over the next transition region. This weight loss is due to both dehydration and the ferrocyanide reactions. 

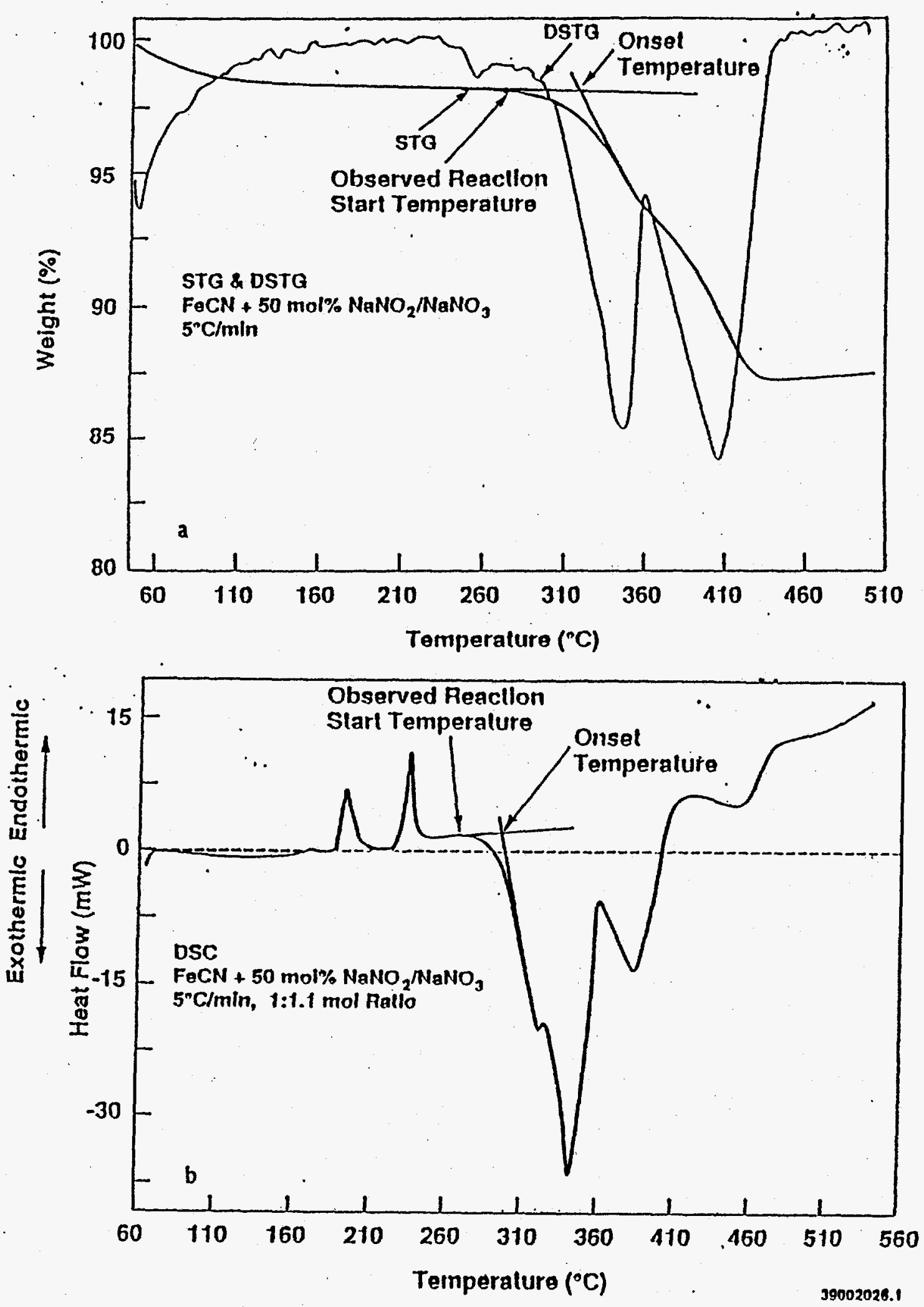

FIGURE 2. Thermal analysis of a ferrocyanide with 50 mol\% nitrate and nitrite. Plot (a) is a DSC scan, and plot (b) is the STG thermogram. 
Similar weight losses were also observed in simulated ferrocyanide containing waste materials.

A small weight gain is observed in some of the quarter segments from both cores 34 and 36 , while other samples exhibited no weight change or a small weight gain. Both weight gains and weight losses were al so observed in the simulated ferrocyanide containing waste materials.

CONCLUSIONS

The data obtained from the characterization of waste from tank 241-C-112 indicates that the concentration of ferrocyanide in this tank is low $1<2.5$ wt\% cyanide). The data also indicates that the ferrocyanide is not homogeneously distributed throughout the tank, and it appears that a heel containing low concentrations of ferrocyanide may exist in this tank. Significant water (40 to $60 \mathrm{wt} \%$ ) is present in this tank which increases the safety of the ferrocyanide material in this tank. 
TABLE 1. Analyses Performed on Tank 241-C-112 Core Samples

\section{QUARTER SEGMENT LEVEL ANALYSES}

\begin{tabular}{ccc} 
Direct & Fusion/Dissolution & Water Leach \\
\hline \hline Total Orangic Carbon & GEA & $\begin{array}{c}\text { Anions by } \\
\text { Ion Chromatography }\end{array}$ \\
DSC & ${ }^{90}$ Sr & Cyanide \\
STG & ICP & \\
Cyanide & & \\
Wt\% Water & &
\end{tabular}

CORE COMPOSITE ANALYSES

\begin{tabular}{cccc} 
Direct & Fusion/Dissolution & Acid Digestion & Water Leach \\
\hline Carbon Analyses & ICP & ICP & ICP \\
Mercury & Total ATpha & $\mathrm{Se}$ & GEA \\
pH & Total Beta & $\mathrm{Sb}$ & $\mathrm{pH}$ \\
Cyanide & GEA & $\mathrm{As}$ & $\mathrm{Cr}^{6+}$ \\
Wt\% Water & Uranium & GEA & Ammonia \\
DSC & ${ }^{99} \mathrm{TC}$ & Total Alpha \\
TGA & ${ }^{90} \mathrm{Sr}$ & Total Beta \\
Semi-VOA & ${ }^{79} \mathrm{Se}$ & GEA \\
VOA & ${ }^{59 / 63} \mathrm{Ni}$ & & ${ }^{3} \mathrm{H}$ \\
TOX/EOX & Pu Isotopics & & \\
${ }^{14} \mathrm{C}$ & $\mathrm{U}$ Isotopics & & \\
Rheology & AEA & & \\
Particle Size & & &
\end{tabular}


TABLE 2. Results of Chemical Analyses

\begin{tabular}{|c|c|c|c|c|c|c|}
\hline \multirow[b]{2}{*}{ Sample } & \multicolumn{4}{|c|}{ CONCENTRATION (wt\%) } & \multicolumn{2}{|c|}{ ACTIVITY (uCi/g) } \\
\hline & Nitrate & Nitrite & Cyanide $^{b}$ & TOC & ${ }^{137} \mathrm{Cs}$ & ${ }^{90} \mathrm{Sr}$ \\
\hline C34-1D & 7.9 & 6.0 & 0.19 & 0.24 & 240 & 1310 \\
\hline$-2 B$ & 7.0 & 5.4 & 0.16 & 0.20 & 610 & 4860 \\
\hline$-2 C$ & 6.5 & 4.9 & 0.14 & 0.10 & 800 & 1140 \\
\hline$-2 D$ & 6.0 & 4.6 & 0.12 & 0.15 & 510 & 2510 \\
\hline COMPOSITE & 7.2 & 5.5 & 0.16 & & & 3510 \\
\hline C $35-2 D$ & 4.4 & 3.5 & 0.08 & 0.26 & 700 & 3210 \\
\hline C36-1C & 6.2 & 4.8 & 0.11 & 0.82 & 410 & 400 \\
\hline-10 & 6.7 & 5.1 & 0.12 & 0.49 & 1240 & 15 \\
\hline$-2 A$ & 6.6 & 4.9 & 0.12 & 0.39 & 880 & 19 \\
\hline$-2 B$ & 4.3 & 3.0 & 0.07 & 0.27 & 530 & 71 \\
\hline$-2 C$ & 4.6 & 3.2 & 0.08 & 0.29 & 100 & 144 \\
\hline$-2 D$ & 5.1 & 3.5 & 0.09 & 0.23 & 35 & 199 \\
\hline COMPOSITE & 5.6 & 4.1 & 0.10 & 0.31 & & 507 \\
\hline
\end{tabular}

(a) The samples are labeled by core and quarter segment. The core is indicated by $C$ and the core number following the $C$. The number after the hyphen is the segment number with the higher number being closer to the bottom. The letter is the quarter segment with $A$ being the top 4.75 inches and $D$ being the bottom 4.75 inches.

(b) Free Cyanide 
TABLE 3. Differential Scanning Calorimetric Data for Tank 241-C-112

\begin{tabular}{|c|c|c|c|c|c|c|c|c|c|}
\hline \multirow[b]{2}{*}{ Sample } & \multicolumn{3}{|c|}{ Transition $\# 1$} & \multicolumn{3}{|c|}{ Transition 2} & \multicolumn{3}{|c|}{ Transition 3} \\
\hline & Rarige & Onset & Enthalpy & Range & Onset & Enthalpy & Range & Onset & Enthalpy \\
\hline$C 34-2 B$ & $30-240$ & 30 & $84 \pi$ & $260-300$ & 27 & -12 & $300-400$ & 349 & \\
\hline C34-2C & $30-240$ & 30 & 795 & $260-300$ & 26 & -13 & $300-400$ & 360 & \\
\hline$C 34-2 D$ & $33-240$ & 33 & 930 & $260-300$ & 28 & -17 & $300-400$ & 347 & \\
\hline G34 Comp & $34-240$ & 34 & 734 & $260-300$ & 27 & -11 & $300-400$ & 357 & \\
\hline C35-2D & $34-195$ & 34 & 780 & $225-290$ & 230 & -12 & & & \\
\hline C.36-1C & $34-240$ & 34 & $107 d$ & $260-300$ & 267 & -11 & $300-380$ & 301 & 3 \\
\hline$C 36-10$ & $32-230$ & 32 & 1310 & $260-310$ & 27 & -16 & This trar & sition not & quanttflable \\
\hline$C 36-2 A$ & $30-230$ & 30 & $11+0$ & $277-300$ & 28 & -10 & $300-400$ & 305 & 3 \\
\hline$C 36-2 B$ & $33-235$ & 30 & 870 & $260-325$ & 298 & -9 & $325-400$ & 330 & 2 \\
\hline C36-2C & $32-240$ & 32 & 830 & This tran & sition not & quantiflable & $305-407$ & 320 & 36. \\
\hline
\end{tabular}




\section{REFERENCES}

Burger, L. L. 1984. Complexant Stability Investigations, - Task 1. Ferrocyanide Solids. PNL-5441, Pacific Northwest Laboratory, Richl and, Washington.

Burger, L. L. and R. D. Scheele. 1988. Interim Report on Cyanide Safety Studies. PNL-7175, Pacific Northwest Laboratory, Richland, Washington.

Burger, L. L. and R. D. Scheele. 1991. The Reactivity of Cesium Nickel Ferrocyanide Towards Nitrate and Nitrite Salts. PNL-7550, Pacific Northwest Laboratory, Richland, Washington.

Cooper, V. R. 1957. Chemical Research and Development Monthly Report and Quarterly Synopsis (U). HW-49419C (SECRET), Hanford Atomic Works Operation, Richland, Washington.

Eiter, K., O. Voge1, and H. Michl. 1954. "Cyanide Safety Explosives", Austrain Patent 176784 (1953), CA 48, 1004 (1954).

Hepworth, J. L., E. D. McClanahan, and R. L. Moore. 1957. Cesium Packaging Studies--Conversion of Zinc Ferrocyanide to a Cesium Chloride Product. HW48832, Hanford Atomic Works Operation, Richland, Washington.

Mckinley, S. G., L. R. Greenwood, E. W. Hoppe, J. M. Tingey, and M. W. Urie. 1992. "Single Shell Tank Waste Characterization Project and Safety Analysis Project Core 34 Data Report (Tank 241-C-112)", Letter Report to Westinghouse Hanford Company, Richland, Washington.

Mckinley, S. G., L. R. Greenwood, E. W. Hoppe, J. M. Tingey, and M. W. Urie. 1992. "Single Shell Tank Waste Characterization Project and Safety Analysis Project Core 35 Data Report (Tank 241-C-112)", Letter Report to Westinghouse Hanford Company, Richland, Washington.

Mckinley, S. G., L. R. Greenwood, E. W. Hoppe, J. M. Tingey, and M. W. Urie. 1992. "Single She 11 Tank Waste Characterization Project and Safety Analysis Project Core 36 Data Report (Tank 241-C-112)", Letter Report to Westinghouse Hanford Company, Richland, Washington.

Sax, I. N. 1957. Dangerous Properties of Industrial Materials. Reinhold, New York.

Scheele, R. D., L. L. Burger, J. M. Tingey, S. A. Bryan, G. L. Borsheim, G. L., B. C. Simpson, R. J. Cash, and H. H. Cady. 1991. Ferrocyanide-Containing Waste Tanks: Ferrocyanide Chemistry and Reactivity. Environmental Remediation 91, Richland, Washington.

Schmidt, W. C. and M. J. Stedwe11. 1954. Production Test 221-T-18 Scavenging of First Cycle Waste. HW-33252, General Electric Company, Richland, Washington.

Sloat, R. J. 1954. TBP NIckel Ferrocyanide Scavenging Flowsheet. HW-30399, General Electric Company, Richland, Washington. 
TABLE 4. Scanning Thermogravimetric Data for Tank 241-C-112

Weight Loss (\%)

\begin{tabular}{lccc} 
Sample & Transition \#1 & Transition \#2 & Transition \#3 \\
\hline & 52 & 5.4 & -0.6 \\
C34-2B & 45 & 4.0 & -0.3 \\
C34-2C & 33 & 6.3 & 0 \\
C34-2D & 35 & 6.1 & -0.6 \\
C34-COMPOSITE & & & \\
& 42 & 6.0 & 0 \\
C35-2D & & & \\
& 46 & 8.9 & -0.3 \\
C36-1C & 52 & 2.0 & -0.2 \\
C36-1D & 52 & 1.9 & -0.2 \\
C36-2A & 38 & 3.1 & -0.1 \\
C36-2B & 41 & 3.8 & 0 \\
C36-2C & 47 & 3.5 & 0.3 \\
C36-2D & 44 & 2.9 & 0.3 \\
C36-COMP & & &
\end{tabular}

